\title{
Assessment of Knowledge and Attitude of Nurses towards Ionizing Radiation during Theatre/Ward Radiography
}

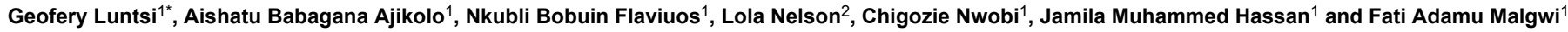

${ }^{1}$ Department of Medical Radiography, College of Medical Sciences, University of Maiduguri, Borno State, Nigeria

${ }^{2}$ Department of Nursing Sciences, College of Medical Sciences, University of Maiduguri. Borno State, Nigeria

"Corresponding author: Geofery Luntsi, Department of Medical Radiography, College of Medical Sciences, University of Maiduguri, Borno State, Nigeria, Tel: +2347035512622; E-mail: geostuffy@unimaid.edu.ng

Received date: Mar 29, 2016; Accepted date: Apr 29, 2016; Published date: May 07, 2016

Copyright: (c) 2016 Luntsi G, et al. This is an open-access article distributed under the terms of the Creative Commons Attribution License, which permits unrestricted use, distribution, and reproduction in any medium, provided the original author and source are credited.

\begin{abstract}
Title: Assessment of Knowledge and Attitude of Nurses towards Ionizing Radiation during Theatre/Ward Radiography

Objective: To assess the knowledge and attitude of nurses towards radiation protection In Maiduguri metropolis.

Methods: A descriptive cross-sectional survey design was used. A quota sampling technique was used to draw a total of 188 registered nurses from three tertiary hospitals in Maiduguri metropolis; University of Maiduguri Teaching Hospital (UMTH), Federal Neuro-Psychiatric Hospital Maiduguri (FNPH), and State Specialist Hospital Maiduguri (SSH) participated in the study. Data was obtained using a 14- item self completion questionnaire that was administered to nursing staff of these hospitals. The questionnaire was divided into 2 sections. Section A; on demographic data and Section B; on knowledge and attitude. Data obtained were analyzed using SPSS version 18.0 and descriptive statistics was used for the analysis.
\end{abstract}

Results: There were more female than male participants with a ratio of $1.09: 1$. Majority of the nurses (74\%) were below the age of forty (40). Most of the nurses $68(36.2 \%)$ had diploma as their highest qualification followed by 61 $(32.4 \%)$ certificate holders. The level of knowledge on radiation was found to be good and positive attitude towards radiation during ward/theater radiography.

Conclusion: Findings of this study revealed that nurses within Maiduguri metropolis had good knowledge of ionizing radiation, although their attitude towards radiation protection during ward/theater radiography is still less than required.

Keywords: Knowledge; Attitude; Radiation; Nurses; Ward; Theater; Radiography

\section{Introduction}

Radiation has always been present in our environment; however, mankind was not directly aware of its existence until the end of the 19 th century, when flurries of scientific discoveries were made [1]. The risk of radiation awareness among the people by the media is aggressive and exaggerated which creates several misconception, confusion and erroneous beliefs that exist with regard to in-hospital radiation hazards. Studies have documented that most people overestimate the risk of industrial radiation and underestimate the risk of medial radiation application [2].

Ionizing radiation in medical imaging is one of the powerful diagnostic tools in medicine [3], several studies have revealed that many doctors have reported that to complete their diagnosis they always sent their patients for a radiologic examination [4]. Although all medical interventions have potential benefits, but it's potential risks should not be ignored [3].

The potential risks of radiation comprises of stochastic effect of which probability increases with dose and deterministic effect of which severity increases with dose [5]. Cancer induction and genetic effects are stochastic effects while cataracts, blood dyscrasias and impaired fertility are examples of deterministic effects [5]. Therefore, before undertaking any radiological examination, it is important that the physician, radiologist and radiographer all understand the potential risks of radiation and also its advantages or benefits to the patients [5].

Reduction of exposure time, increasing distance from source, and shielding of patients and occupational workers have proven to be of great importance in protecting patients, personnel, and members of the public from the potential risks of radiation [5]. These three radiation protection actions of "time-distance-shielding" are the triad of radiation protection. Radiation protection is a general term applied to the profession or science related to protecting man and the environment from radiation hazards.

Nurses posted to the radiology department and those in the wards and theatre where radiography procedures are done, offers professional care to patients before, during and after radiologic procedures. They help to book reassure and prepare patients for special radiologic procedures and as well provide after care to patients after the procedures. Nurses also help to support the patient during the procedure and also prepare the equipment and instruments needed during the examination. Nurses working in departments, units or 
Page 2 of 5

wards where ionizing radiation take place need to be knowledgeable about radiation and radiation protection practices so as to be able to give the patient the rightful information and protect themselves as well as the patients and the general public from unnecessary radiation exposure.

The researchers observed that during radiographic examinations on the ward, some nurses are extremely afraid to stay within the vicinity during radiation exposures, or just move some distance away but on sitting the radiographer with the mobile X-ray machine on the ward, they leave you with the patient and do not even want to come closer and help in lifting the patient even while no exposure is going on, and despite the reassurance and radiation protection measures employed by the radiographer. These reactions of some nurses towards ionizing radiation and the need to understand why they behave differently prompted the researchers' interest to find out the level of knowledge on ionizing radiation and their attitude towards radiation protection. This study aimed to assess the knowledge and attitude of nurses towards radiation protection during ward and theatre radiography.

\section{Materials and Methods}

Descriptive survey design was used for the study. The study was conducted in three tertiary hospitals in Maiduguri Borno State, Northeastern Nigeria, and the target population was all nurses working in the departments, units or wards where radiographers may sometimes be requested to carry out certain radiographic examinations on patients who are critically ill and who may not be able to be moved to the radiology department for their examination, like patients in the intensive care unit (ICU), orthopedic ward, accident and emergency unit among others. With the use of quota sampling technique, 95 Nurses were drawn from University of Maiduguri Teaching Hospital (UMTH), 55 from Federal Neuropsychiatric Hospital (FNPH), and 38 from State Specialist Hospital (SSH) making a total of 188 Nurses. A structured close ended 14- items questionnaire was used to collect data. The questionnaire was divided into 2 sections.
Section A consisted of demographic data and Section B consisted of items on knowledge and attitude towards radiation protection during radiography. Data was collected for a period of one month and analyzed using statistical package for social sciences (SPSS), version 18.0 and presented using frequency distribution tables and percentages. Ethical clearance was obtained from research and ethical committee of UMTH to conduct the study. This was done by submitting a letter together with the research proposal to the research and ethical committee of UMTH for permission to conduct the research. After two weeks of submission, approval was granted signed by the chairman of the committee to conduct the study. The approval letter was presented to the heads nursing in each of the hospital for permission to administer the questionnaire. Informed consent was sought from all the participants and acceptance to participate in the study was considered as consent. Confidentiality of the data collected was maintained as no name of any nurse was mentioned in the research.

\section{Results}

A total of 230 questionnaires were distributed and 188 were filled and returned within a period of one month giving a response rate of $82 \%$. The study found that female respondents were 98 (52\%) while male were 90 (48\%).The respondents age ranged from 21 to 46 years and above with a mean age of 26.5 years. Respondents with the age group of $26-30$ years had the highest while those within the age group of 46 and above had the least frequency. Most of the nurses 68 (36\%) had diploma as their highest level of qualification followed by certificate holders who were 61 (32\%). Only one nurse (1\%) had a PhD and two of them (2\%) had MSc while $56(30 \%)$ had BSc. In years of experience, $84(44.7 \%)$ had practiced for $0-5$ years while $23(12.2 \%)$ had practiced for 16-20 years. University of Maiduguri Teaching Hospital had 95 (50.5\%) of the participants while 55 (29.3\%) were from FNPH and 38 (20.2\%) from SSH (Table 1).

\begin{tabular}{|l|l|l|l|l|l|}
\hline Demographic data & & Total & & & \\
\hline & & UMTH & FNPH & SSH & TOTAL \\
\hline & & N & N & N & N \\
\hline Sex & Male & $49(52 \%)$ & $30(55 \%)$ & $11(29 \%)$ & $90(48 \%)$ \\
\hline Age group & Female & $46(48 \%)$ & $25(45 \%)$ & $27(71 \%)$ & $98(52 \%)$ \\
\hline & $21-25$ & $6(6 \%)$ & $14(25 \%)$ & $10(26 \%)$ & $30(16 \%)$ \\
\hline & $26-30$ & $26(27 \%)$ & $20(36 \%)$ & $6(15 \%)$ & $52(27.7 \%)$ \\
\hline & $31-35$ & $18(19 \%)$ & $11(20 \%)$ & $2(5 \%)$ & $31(16.5 \%)$ \\
\hline & $36-40$ & $18(19 \%)$ & $1(2 \%)$ & $7(18 \%)$ & $26(13.8 \%)$ \\
\hline & $41-45$ & $19(20 \%)$ & $3(5 \%)$ & $7(18 \%)$ & $29(15.4 \%)$ \\
\hline & 46 and above & $8(8 \%)$ & $6(11 \%)$ & $6(16 \%)$ & $20(10.6 \%)$ \\
\hline & Certificate & $22(23 \%)$ & $17(31 \%)$ & $22(58 \%)$ & $61(32 \%)$ \\
\hline & Diploma & $34(36 \%)$ & $24(44 \%)$ & $10(18 \%)$ & $68(36 \%)$ \\
\hline & BSc & $36(38 \%)$ & $14(25 \%)$ & $6(11 \%)$ & $56(30 \%)$ \\
\hline
\end{tabular}


Citation: Luntsi G, Ajikolo AB, Flaviuos NB, Nelson L, Nwobi C, et al., (2016) Assessment of Knowledge and Attitude of Nurses towards lonizing Radiation during Theatre/Ward Radiography. J Nurs Care 5: 342. doi:10.4172/2167-1168.1000342

Page 3 of 5

\begin{tabular}{|l|l|l|l|l|l|}
\hline & MSc & $2(2 \%)$ & $0(0 \%)$ & $0(0 \%)$ & $2(1 \%)$ \\
\hline & PhD & $1(1 \%)$ & $0(0 \%)$ & $0(0 \%)$ & $1(1 \%)$ \\
\hline Years of professional practice & $0-5$ & $29(30.5 \%)$ & $37(67.3 \%)$ & $18(47.4 \%)$ & $84(44.7 \%)$ \\
\hline & $10-J u n$ & $16(16.8 \%)$ & $7(12.7 \%)$ & $4(10.5 \%)$ & $27(14.4 \%)$ \\
\hline & $15-$ Nov & $24(25.2 \%)$ & $1(1.8 \%)$ & $4(10.5 \%)$ & $29(15.4 \%)$ \\
\hline & $16-20$ & $15(15.8 \%)$ & $4(7.2 \%)$ & $4(10.5 \%)$ & $23(12.2 \%)$ \\
\hline & Above 20 & $11(11.6 \%)$ & $69(10.9 \%)$ & $8(21.1 \%)$ & $25(13.3 \%)$ \\
\hline
\end{tabular}

Table 1: Demographic characteristics of respondents.

Table 2 shows that, $150(79.7 \%)$ agreed radiation used in medical imaging can possibly cause harmful effects while $30(16.5 \%)$ disagreed to it, and 8 (4.3\%) do not know. Majority, 149 (79.3\%) of the nurses agreed that X-ray used in medical imaging has more benefit than harm. The remaining $31(16.5 \%)$ answered yes and only 8 (4.3\%) of the population admitted that they don't know. Majority of the nurses, 80 (42.6\%) wrongly assumed that objects in the room emit radiation after an X-ray exposure. Only 56 making $(29.8 \%)$ answered no while 51 (27.1\%) don't know.

\begin{tabular}{|l|l|l|l|l|}
\hline Items & Yes & No & Don't know & Total \\
\hline Radiation can cause harmful effects & $150(79.7 \%)$ & $30(16.5 \%)$ & $8(4.3 \%)$ & $188(100 \%)$ \\
\hline X-rays used in medical imaging cause more harm than benefit & $31(16.5 \%)$ & $149(79.3 \%)$ & $8(4.3 \%)$ & $188(100 \%)$ \\
\hline $\begin{array}{l}\text { Radiation that is used in wards and theatres are more dangerous than } \\
\text { those in the radiology department }\end{array}$ & $49(26.1 \%)$ & $106(56.4 \%)$ & $33(17.6 \%)$ & $188(100 \%)$ \\
\hline Radiation is used for boosting the immune system & $26(13.8 \%)$ & $141(75 \%)$ & $21(11.2 \%)$ & $188(100 \%)$ \\
\hline Generally we receive radiation in our everyday life & $137(72.9 \%)$ & $45(23.9 \%)$ & $5(2.7 \%)$ & $187(100 \%)$ \\
\hline $\begin{array}{l}\text { The lifespan of radiology workers are less compared to other health } \\
\text { workers }\end{array}$ & $92(48.9 \%)$ & $54(28.7 \%)$ & $42(22.3 \%)$ & $188(100 \%)$ \\
\hline Objects in the room emit radiation after an x-ray exposure & $80(42.6 \%)$ & $56(29.8 \%)$ & $51(27.1 \%)$ & $187(100 \%)$ \\
\hline
\end{tabular}

Table 2: Nurses knowledge on radiation.

In Table 3, 142 (75.5\%) of the respondents keep away from patients during radiographic exposure. Only 5 (2.7\%) don't know and 41 (21.8\%) do not.

\begin{tabular}{|l|l|l|l|}
\hline Items & Yes & No & Don't know \\
\hline Staying away from patient during exposure. & $142(75.5 \%)$ & $41(21.8)$ & $5(2.7 \%)$ \\
\hline Use lead apron during radiographic exposure. & $159(84.5 \%)$ & $16(8.5 \%)$ & $13(6.9 \%)$ \\
\hline Coming to the vicinity after x-ray exposure. & $78(41.5 \%)$ & $93(49.5 \%)$ & $16(8.5 \%)$ \\
\hline
\end{tabular}

Table 3: Attitude of nurses towards radiation.

About 159 (84.5\%) use lead apron to protect themselves during radiographic exposures, 13 (6.9\%) don't know and 16 (8.5\%) do not. About $93(49.5 \%)$ come to the vicinity after radiographic exposure while 78 (41.5\%) do not and 16 (8.5\%) don't know.

On cross tabulating educational qualification and attitude, towards radiation protection, it was found that participants with MSc. and above have good radiation protection practice. This is followed by BSc and the least was among certificate holders.
The study also found that positive attitude increase with increase in years of professional practice. Those with a working experience of 16-20 years and 20 years and above had good positive attitude to radiation protection and least was those with practice experience of $0-5$ years (Tables 4 and 5). 


\begin{tabular}{|l|l|l|l|l|l|l|}
\hline Items & Educational level & & & & \\
\hline & Certificate & Diploma & BSc & MSc & PhD & TOTAL \\
\hline Staying away from patient during exposure & $42(68.6 \%)$ & $51(75 \%)$ & $46(82.1 \%)$ & $200 \%)$ & $1(100 \%)$ & $142(75.5 \%)$ \\
\hline Use of lead apron & $49(80.3 \%)$ & $58(85.3 \%)$ & $48(70.6 \%)$ & $2(100 \%)$ & $1(100 \%)$ & $159(84.6 \%)$ \\
\hline Come to vicinity after exposure. & $29(47.5 \%)$ & $33(48.5 \%)$ & $28(50 \%)$ & $2(100 \%))$ & $1(100 \%)$ & $93(49.5 \%)$ \\
\hline AVERAGE & $40(65.6 \%)$ & $47(69.6 \%)$ & $40(72.6 \%)$ & $2(100 \%)$ & $1(100 \%)$ & $131(69 \%)$ \\
\hline
\end{tabular}

Table 4: Crosstabulating educational level against attitude toward radiation.

\begin{tabular}{|c|c|c|c|c|c|c|}
\hline Items & Years of practice & & & & & \\
\hline & $0-5$ & 10-Jun & 15-Nov & $16-20$ & 20 and above & TOTAL \\
\hline $\begin{array}{l}\text { Staying away from patient during } \\
\text { exposure }\end{array}$ & $57(67.9 \%)$ & $20(74.1 \%)$ & $23(79.3 \%)$ & $20(87 \%)$ & $22(88 \%)$ & $142(75.5 \%)$ \\
\hline Use of lead apron & $71(84.5 \%)$ & $21(77.8 \%)$ & $23(79.3 \%)$ & $21(91.3 \%)$ & $23(92 \%)$ & $159(84.6 \%)$ \\
\hline Coming to vicinity after exposure. & $32(38.1 \%)$ & $14(51.9 \%)$ & $21(72.4 \%)$ & $13(56.5 \%)$ & $13(52 \%)$ & $93(49.5 \%)$ \\
\hline AVERAGE & $53(63.5 \%)$ & $18(67.9 \%)$ & $22(77 \%)$ & $18(78.3 \%)$ & $19(77.3 \%)$ & $131(69 \%)$ \\
\hline
\end{tabular}

Table 5: Cross tabulating years of practice against attitude toward radiation.

\section{Discussion}

A total of 230 questionnaires were distributed, 188 were filled and returned within a period of one month giving a response rate of $81.7 \%$. Males were 90 (48\%) while 98 (52\%) were female with age range from 21-46 years and above and a mean age of 26.5 years. The higher number of female participants could perhaps be because the nursing profession is viewed as a female profession and dominated by them. This is in agreement with a study by Alotaibe and Saeed [6] and Maliro [7] who also found higher frequency of female.

The study found majority of the participants 129 (68\%) to be certificates and diploma holders, followed by bachelors of nursing science degree (BNSc) holders with $5(30 \%)$ while masters of science degree $(\mathrm{MSc})$ and doctor of philosophy degree (Ph.D) were the least with $2(1 \%)$ and $1(0.5 \%)$ respectively. These findings were similar to that of Alotaibe and Saeed6 who found that most of the nurses had diploma as their highest qualification. This could be because there are more certificates and diploma awarding nursing institutions than those awarding bachelors of nursing sciences degree (BNSc), master's degree (MSc) and doctor of philosophy degree (Ph.D) as obtainable within the study locality and developing nations like Nigeria. UMTH had the highest number of BSc nurses with 36 (37.9\%) followed by FNPH 14 $(25 \%)$ and SSH with the least having a frequency of $6(11 \%)$.

Working experience shows that, 84 (44.7\%) of the respondents had working experience of five years and below signifying that most of the respondents were still young in professional practice.

The participants had good knowledge of ionizing radiation and about $60.4 \%$ knew the source, benefit and the potential harm of ionizing radiation. This is probably due to general knowledge about radiation and its associated hazards. These findings are in agreement with that of Rassin et al. [4], who found that majority (70\%) of the nurses had average knowledge on radiation. However studies conducted by Alotaibe and Saeed [6] and Maliro [7] revealed that nurses lack knowledge on radiation sources and radiation protection methods.

The study also found that the respondents had positive (good) attitude towards ionizing radiation during theatre and ward radiography, whereas 132 (70\%) of them practice good radiation protection by shielding (use of lead apron) and keeping distance from patients during radiographic exposures. This is perhaps because of the fear of radiation motivating them either ignorantly or intentionally to adopt good radiation protection practices. This findings are different from that of Rassin et al. [4] who found that though there was an average knowledge on radiation, most of the participants do not follow radiation safety methods.

The study found that the level of education attained by the participants in this study, impacted positively on their attitude towards radiation protection because good radiation protection practice increased as the participants' level of education increased as seen in this study. This might be as a result of the increased information due to higher level of exposures that might come as a result of increased level of education. This finding are not similar to that of Alotaibe and Saeed [6], Maliro [7], and Urushizaka [8] who found that there is no influence of level of education on attitude of nurses towards radiation protection.

This study also revealed that as participants' years of practice increased, their attitude towards radiation also got better. This might be because of the abated fear and misconceptions about ionizing radiation that may accrue over the length of years of practice. This is not in agreement with to the findings of Alotaibe and Saeed [6] and Maliro [7], who found that years of professional practice did not affect the attitude towards radiation. However, geographical location, place and nature of practice should not be ignored as this could also impact on their attitude towards ionizing radiation. 
Citation: Luntsi G, Ajikolo AB, Flaviuos NB, Nelson L, Nwobi C, et al., (2016) Assessment of Knowledge and Attitude of Nurses towards lonizing Radiation during Theatre/Ward Radiography. J Nurs Care 5: 342. doi:10.4172/2167-1168.1000342

Page 5 of 5

\section{Conclusion}

Findings from this study showed that participants had good knowledge and attitude towards ionizing radiation during theatre and ward radiography and this was influenced by the level of education attained and years of professional practice, however, more needs to be done to improve on the curriculum content on ionizing radiation in the nursing institutions and nurses should also be encouraged to pursue further studies to meet up with the current trend of evidence based practice.

We recommend seminars and symposium on a regular basis within the hospitals to educate all the staff on radiation protection.

\section{References}

1. Bushberg, JT, Seibert JA, Edwin ML and Boone MJ (2002) Essential physics of medical imaging, 2nd ed., Lippincott Williams and Wilkins. Philadelphia.

2. Mubeen SM, Abbas Q, Nisar N (2008) Knowledge About Ionizing And Non-Ionizing Radiation Among Medical Students. Ayub Medical College, Abbotabad, Karachi, Pakistan 20: 118-20.
3. Mojiri M, Moghimbeigi A (2008) Awareness and attitude of radiographers towards radiation protection, Journal of Paramedical Sciences 2: 4-5.

4. Rassin M, Granat P, Berger M, and Silner E (2005) Attitude And Knowledge Of Physicians and Nurses About Ionizing Radiation, Journal Of Radiology Nursing 24: 26-30.

5. Grover SB, Kumar J, Gupta A, Hanna L (2002) Protection against radiation hazards: regulatory bodies, safety norms, dose limits and protection devices, Indian journal of radiology and imaging. 12: 157-67.

6. Alotaibe M, Saeed R (2006) Radiology Nurses Awareness of Radiation, Journal of Radiology Nursing 125: 7-12.

7. Maliro FMJ (2011) Ionizing Radiation Protection Awareness among Nurses Working At Queen Elizabeth Central Hospital Malawi, PhD, Department of Health Sciences, University of Johannesburg.

8. Urushizaka M, Noto Y, Ogura N, kitajima M, Nishizawa Y, et al. (2013) Changes in Nurses Impression of Radiation after attending Educational Seminars on Radiation, Radiation Emergency Medicine 2: 35-42. 